\title{
EDUCAÇÃO INTERCULTURAL: DIREITOS, DESAFIOS E PROPOSTAS DE DESCOLONIZAÇÃO E DE TRANSFORMAÇÃO SOCIAL NO BRASIL
}

\author{
Entrevista com Gersem José dos Santos Luciano
}

GERSEM JOSÉ DOS SANTOS LUCIANO é índio Baniwa e professor adjunto da Universidade Federal do Amazonas (UFAM). Possui graduação em Filosofia pela UFAM, com mestrado e doutorado em Antropologia Social pela Universidade de Brasília (UnB). Recebeu o Prêmio CAPES de Teses em 2012, com pesquisas concentradas nos seguintes temas: educação indígena, política indigenista, movimento indígena e desenvolvimento sustentável.

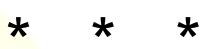

CIMEAC: Qual o papel da escola indígena intercultural em um contexto de colonialidade e de opressão dos povos indígenas? Quais as demandas indígenas para a escola do século XXI num país multicultural como o Brasil?

Gersem José dos Santos Luciano (GJSL): Em primeiro lugar é importante entendermos que a instituição escolar assim como a ideia de educação intercultural são invenções do colonizador. São ferramentas, instrumentos, discursos e modos de pensar e fazer dos colonizadores para atingir determinados objetivos. A instituição escolar, por exemplo, foi criada e é mantida para garantir a manutenção, a reprodução e a continuidade dos modos de pensamento, das relações sociais, econômicas, políticas e culturais próprios da sociedade moderna, liberal, industrial, mercantilista, capitalista, tecnicista. Ou seja, a escola tem a missão de reprodução do modus operandi, modos pensanti e do modus vivendi da sociedade ocidental moderna, portanto de uma determinada sociedade, situada em um determinado período de tempo e espaço histórico. Acontece que ao longo do tempo essa cosmologia foi sendo constituída, de modo sofisticado, sistêmico e pretensamente imperativo, portanto, universal. Dessa forma a escola foi sendo conhecida e imposta como um imperativo necessário e imprescindível para a existência, sobrevivência e desenvolvimento das sociedades humanas. Foi assim que a escola se tornou um instrumento mais poderoso e eficaz da colonização e da colonialidade ainda vigente em nossos dias. Com o avanço da liberdade e da autonomia de pensamento nas antigas colônias europeias, setores e sujeitos sociais e intelectuais iniciaram uma forte crítica a esta cultura sistêmica de colonialidade 
e começaram a esboçar ideias alternativas para possível superação ou enfrentamento da cultural colonial enraizada nas sociedades colonizadas. Assim surgiram as ideais de pluriculturalismo, multiculturalismo e interculturalismo ou interculturalidade. Para nós, a ideia de interculturalidade pode ser entendida a partir de duas perspectivas: abrir caminhos para 0 reconhecimento e reposição dos sujeitos colonizados, subalternizados, subjugados, silenciados, dominados e alijados de suas autonomias societárias e cosmológicas a uma posição de diálogo, de interação, de coexistência e convivência dialética. A outra perspectiva é a de interculturalidade como promessa de diálogo discursivo, ideológico e ainda colonizador. Aqui o discurso de interculturalidade é usado para encobrir, esconder, mascarar e, no máximo, amenizar os efeitos da colonialidade, materializada por meio de práticas de exclusão, injustiça, desigualdade, violência e racismo contra os sujeitos coletivos que se negam e resistem a sucumbir e aderir de forma subalterna aos modos de vida da sociedade capitalista profundamente predatória, anti-humana e anti-cosmo. Esta segunda perspectiva significa praticamente e, de modo ainda pior, a continuidade do colonialismo racista, na media em que confunde, manipula, desarma e desempodera os sujeitos colonizados para se acomodarem diante do processo colonizador, muitas vezes culpando o próprio colonizado de seus fracassos e justificando a necessidade de sua colonização como generosidade do colonizador.

A escola indígena intercultural tem se orientado pela primeira perspectiva, ou seja, buscando empoderar os sujeitos indígenas para um diálogo menos desigual, menos assimétrico e menos hierarquizado intra e extra aldeia/escola. Na perspectiva das comunidades indígenas, a escola indígena intercultural deve ajudar na compreensão da lógica de pensamento e funcionamento da sociedade moderna envolvente. Isso porque os povos indígenas entendem que a sua derrota parcial no processo colonial foi resultado fundamentalmente pelo não conhecimento dos modus operandi dos conquistadores.

Assim, para a defesa de suas culturas, de seus conhecimentos e de seus direitos na atualidade os povos indígenas necessitam dominar ao máximo possível os modus pensanti e operandi dos colonizadores. Assim, dominar os conhecimentos dos brancos não significar tornar-se branco ou abdicar-se de seus modos tradicionais de vida. Significa que, de posse dos conhecimentos dos brancos e dos seus modos de pensar, agir e viver, a chance de estabeleceram estratégias eficazes de defesa, resistência e garantia de seus direitos e de seus interesses é muito maior, transformando os próprios conhecimentos dos brancos não contra os brancos, mas, em favor dos direitos coletivos indígenas. Isso de fato pode e tem ajudado em diálogos menos desiguais entre os povos indígenas e o Estado e a sociedade nacional dominante. No campo político-pedagógico estamos falando de uma lógica de complementariedade de conhecimentos, saberes, cosmologias e 
epistemologias, própria da racionalidade ontológica dos povos ameríndios. Aqui não se trata de disputa, concorrência, paralelismo ou antagonismos, mas de soma de possibilidades de horizontes.

O problema da escola indígena intercultural é quando ela é idealizada numa perspectiva de missão idealista e salvacionista, ignorando a enorme diversidade de autonomias e alteridades dos sujeitos individuais e coletivos envolvidos e das complexas e profundas tensões e conflitos sociais, econômicos, políticos, raciais e epistemológicos que existem e operam ao seu redor e que exercem pressões diretas sobre sua funcionalidade políticopedagógica sobre as quais possui pouco ou nenhuma governabilidade. Há, por exemplo, pessoas muitas vezes bem intencionadas que esperam que a escola indígena intercultural harmonize as relações internas dos povos indígenas ou que dê conta da integridade e continuidade das culturas, línguas e conhecimentos tradicionais e ao mesmo tempo converta, pacifique ou colonize/civilize o mundo externo "extra-aldeia", idealizando uma sociedade ou humanidade de paz, solidária, fraterna, justa, igual, perfeita. Sabemos das grandes limitações da ideia de interculturalidade principalmente no campo da coexistência e da convivência prática. Mesmo os mais progressistas defensores da idéia conseguem avançar ao patamar de tolerância, mas não abrem mão de seus cômodos modos pensanti, operandi e vivendi.

Reconhecemos que a proposta de escola indígena intercultural está contribuindo para transformar a escola tradicional para índios - totalmente colonial, negadora de culturas, saberes e línguas indígenas - em escolas com forte protagonismo indígena e com currículos menos eurocêntricos. Uma escola dinâmica e em movimento, portanto uma escola praticando a cultura do diálogo, da complementariedade e da dialética intercultural. Dialética intercultural significa que as distintas culturas, os distintos saberes e as distintas cosmovisões presentes, envolvidas e acionadas pela escola indígena estão em constante movimento circular, interativo e de conexões intermundos, sem a arrogância vertical e hegemônica da ciência ocidental colonizadora. Mas ainda precisamos caminhar muito para chegarmos a ter escolas indígenas verdadeiramente indígenas. Para que as escolas indígenas sejam interculturais da perspectiva indígena, primeiro ela precisa ser indígena de direito e de fato. Ela ainda não é. Uma vez verdadeiramente indígena, então a escola indígena poderá começar a transformar essa escola em escola indígena intercultural em seus termos, segundo suas próprias referências pedagógicas, cosmológicas, ontológicas e epistemológicas.

CIMEAC: A organização social CIMEAC, em uma de suas frentes de trabalho, atua desde a perspectiva da Educação Popular. Gostaríamos de saber se o discurso da emancipação e transformação social, a partir de sujeitos críticos e proativos nos processos de tomada de decisões, dialoga com os processos educativos pensados para a escola indígena. Além disso, qual a 
intencionalidade política declarada na organização das práticas pedagógicas e currículos de escolas indígenas? Como o conhecimento científico eurocêntrico seria tratado neste contexto educacional intercultural?

GJSL: Sem dúvida que a escola indígena atual projetada estratégica e intencionalmente como escola indígena própria - específica, diferenciada, autônoma - assume como missão institucional no campo político-pedagógico a transformação da sociedade em que está contextualmente e historicamente situada, começando pela sua própria transformação. Os sujeitos da escola indígena vivem atualmente em um contexto bastante hostil e ameaçador em seus direitos de viver. Um contexto construído ao longo de meio milênio de violenta colonização. Mais do que conhecer essa triste história, os sujeitos indígenas da escola precisam, de posse dessa consciência histórica, projetar o seu futuro que se deseja muito diferente e muito melhor. A escola indígena é parte orgânica do plano ou projeto societário de vida de cada povo indígena. A escola, sendo parte orgânica e estratégica da coletividade, assume então a tarefa de orientar e formar sujeitos individuais conscientemente orgânicos e coresponsáveis pelo bem viver de todos, que só será alcançado com a superação da cultura colonial destruidora, dominadora, negadora e excludente. Não são apenas os sujeitos educandos ou educadores que se quer orgânicos, mas a própria instituição formadora. O coletivo politicamente engajado só pode ser gerado em uma instituição escolar engajada. Daí a tamanha importância de se ter escolas indígenas próprias e autônomas, ou seja, escolas indígenas verdadeiramente indígenas. Este engajamento politicamente empoderado de sujeitos individuais e coletivos indígenas requer na atualidade acesso e domínio de um conjunto amplo e articulado de conhecimentos tradicionais, escolares e de conhecimentos populares. Dessa forma, os povos indígenas, por meio da escola, não abrem mão de garantirem o acesso mais amplo possível aos conhecimentos encontrados no mundo extra-aldeia, que Ihes interessam, mas, é claro, sem abrir mão do direito de continuarem produzindo, reproduzindo, promovendo e vivenciado os seus conhecimentos próprios. $O$ Bem Viver dos povos indígenas, como um estado de espírito no mundo cósmico mais do que uma qualidade material ou social de vida está relacionado às relações equilibradas dos sujeitos humanos e não humanos que coabitam o cosmo. Assim sendo, o segredo para se alcançar o mais alto nível de Bem Viver para os sujeitos individuais ou/e coletivos implica o cultivo permanente de relações respeitosas, recíprocas, solidárias e, sobretudo, complementares no plano cósmico. Nada precisa ser negado, excludente e concorrente. Ao contrário, tudo pode ser somado, acrescido e aperfeiçoado. Deste modo, os conceitos e as teorias científicas, assim como os conhecimentos indígenas e outros conhecimentos existentes, são formas de ver o mundo que podem dialogar entre si, complementar-se, completar-se, e assim, a humanidade, na 
sua diversidade, poderia ter uma visão mais binocular, mais completa e por isso mesmo mais bela.

CIMEAC: As políticas públicas brasileiras para as questões indígenas apresentam avanços e retrocessos em nosso período histórico denominado democrático. Qual a sua análise sobre as políticas públicas nos governos de Fernando Henrique Cardoso e de Luiz Inácio Lula da Silva? Quais os avanços e os desafios que são colocados para o poder público nos dias de hoje?

GJSL: Nós vivemos nos últimos 30 anos no Brasil transformações importantes na política indigenista e na relação do Estado com os povos indígenas. 0 marco promotor dessas transformações é a Constituição Federal de 1988 que representa até hoje a maior conquista dos povos indígenas em toda história de conquista e colonização europeia. Os 488 anos de colonização antes da referida Constituição tinham um sabor de pessimismo existencial alimentado pelo dramático processo de massacres, genocídios e etnocídios que fizeram desaparecer centenas ou mesmo milhares de povos, línguas, culturas, tradições e civilizações autóctones do continente e do Brasil e pelo vertiginoso declínio populacional, quando, dos mais de cinco milhões de indígenas encontrados em 1500 no Brasil, chegou-se a menos de 100 mil em 1970. A era pós Constituição está marcada para os povos indígenas por um sentimento existencial otimista, mesmo considerando, o atual cenário de ameaças e retrocessos.

É importante destacar os direitos mais importantes conquistados na Constituição Federal de 1988 que podem ser resumidos nos seguintes pontos:

1. Reconhecimento da capacidade civil dos povos indígenas, pondo fim a cinco séculos de dúvida sobre a humanidade e capacidade cognitiva destes. Com isso, a Constituição instaurou um novo marco conceitual e jurídico, abandonando as ideias de integração e assimilação sociocultural dos indígenas pelos colonizadores. Esses conceitos consideravam os índios como uma categoria social transitória, fadada ao desaparecimento. No plano político-administrativo o modelo político pautado em noções de tutela e assistencialismo foi sendo substituído pelo modelo que reconhece e afirma a pluralidade étnica e a autonomia e protagonismo dos povos indígenas como direitos, estabelecendo-se novas relações promotoras e protetoras de direitos entre o Estado e povos indígenas.

2. Reconhecimento do Direito à Diferença, que garante aos povos indígenas, o direito de continuarem vivendo de acordo com suas culturas, tradições e modos de vida permanecendo como tais indefinidamente, ao reconhecer aos índios suas organizações sociais, costumes, línguas, crenças e tradições (Artigo 231). Com isso, os povos 
indígenas deixam de ser percebidos e tratados como transitórios e passam a ser reconhecidos como sujeitos coletivos de direitos permanentes. No plano sociológico, os povos indígenas passam a ser percebidos como parte integrante e permanente da sociedade brasileira. O reconhecimento da capacidade civil e do direito à Diferença formam direitos que mais contribuíram para a superação do processo de extinção dos povos indígenas no Brasil assim como com o processo de organização, empoderamento, autonomia e protagonismo indígena observado nos últimos anos.

3. Reconhecimento dos "direitos originários", com destaque no plano do direito às terras tradicionalmente ocupadas, reafirmando a posse das mesmas como anterior à formação do Estado, existindo, portanto, independentemente de qualquer reconhecimento oficial.

4. A Constituição também assegura aos povos indígenas a utilização de suas línguas e processos próprios de aprendizagem no ensino básico (artigo 210, §2º), por meio da educação escolar indígena. Este enunciado constitucional abriu inúmeras possibilidades para que se desenvolvessem no Brasil experiências mais variadas e ricas em termos de projetos de escolas indígenas autênticas e autônomas do ponto de vista pedagógico e de gestão e de acordo com os planos etnopolíticos de cada povo. $O$ enunciado deste direito continua potencialmente aberto na medida em que possibilita generosamente pensar e construir experiências indígenas com a educação escolar e para além dela.

À luz dos direitos indígenas conquistados na CF 1988, os diferentes governos que atuaram após esse período, empreenderam importantes mudanças no escopo das políticas indigenistas do país. Uma das primeiras mudanças estruturantes na era pós Constituição Federal de 1988 foi a retirada do monopólio da política indigenista da FUNAI, considerada até então, o único órgão titular indigenista. Em consequência disso, entre 1990 e 1991 as responsabilidades pela política indigenista foram distribuídas entre as diversas instâncias ministeriais do Estado. A saúde foi para o Ministério da Saúde em 1990. A educação para o Ministério da Educação em 1991. As questões ambientais para o Ministério do Meio Ambiente. Os programas sociais foram para o Ministério do Desenvolvimento Social. Políticas culturais foram para o Ministério da Cultura e assim por diante, restando à FUNAI a regularização e proteção territorial, a defesa e promoção dos direitos indígenas de um modo geral, além de atuação complementar e colaborativa com outros ministérios.

Ao abolir o monopólio do órgão indigenista na defesa e regulação dos direitos indígenas, o capítulo dos direitos indígenas na Constituição abriu caminhos para novas práticas, experiências e vivências no indigenismo brasileiro. De fato, inovações e novas experiências ocorreram. As novas experiências promoveram o estabelecimento de potenciais parcerias entre 0 
Estado e os povos indígenas, atribuindo ao primeiro, o papel de suprir necessidades básicas como a saúde e a educação e de prover apoio e fomento à implantação de políticas setoriais para a geração de renda, gestão territorial e ambiental das terras demarcadas e preservação das culturas tradicionais. Aos povos indígenas foi reconhecido o protagonismo político na garantia e efetivação de seus direitos e a co-responsabilização no desenvolvimento de políticas públicas de seus interesses.

A título de exemplo citamos alguns dados significativos nos campos de educação e saúde que mostram avanços que nenhum outro segmento da população brasileira apresentou, em termos de crescimento tão expressivo no período. No âmbito da educação escolar indígena, segundo dados do Censo Escolar, em 2002 havia no Brasil 1.706 escolas indígenas e 117.446 alunos indígenas matriculados. Em 2015, já eram 3085 escolas indígenas, 285.303 alunos indígenas matriculados e 20.238 professores indígenas atuando nas escolas indígenas. No âmbito do financiamento os recursos financeiros destinados à educação escolar indígena duplicaram em menos de 10 anos. Em 2004 esses recursos, somando-se os aportes oriundos do Fundo Nacional de Desenvolvimento da Educação Básica (FUNDEB), os do Programa Nacional de Alimentação Escolar (PNAE) e os recursos suplementares estavam em 600 milhões de reais, em 2010 este montante ultrapassou a cifra de um bilhão de reais, reforçado pelos recursos do Plano de Ação Articulado (PAR indígena) e o aumento significativo de alunos indígenas matriculados, aumentando os recursos do FUNDEB e do PNAE.

No campo da saúde indígena também os avanços são perceptíveis. Em 2002, 5654 profissionais de saúde trabalhavam atendendo as aldeias, contando com um montante de recursos de $\mathrm{R} \$ 221.413 .000,00$. Em 1998 era apenas de $R \$ 21.500 .000,00$. Em 2013 este montante subiu para mais de 1 bilhão de reais e com mais de 12000 profissionais de saúde atuando junto às aldeias.

A descentralização da política indigenista, espalhada por vários ministérios, estimulou os mesmos a criarem estruturas administrativas com equipes e orçamentos para atender as demandas indígenas crescentes nas suas respectivas áreas de atuação, ainda que de modo incipiente e no plano mínimo ou básico. Para esses ministérios, a nova realidade não foi uma tarefa fácil considerando que nunca antes tinham trabalhado com a temática indígena. De forma que ao romper a cultura de centralidade da política indigenista em um único órgão, o Estado brasileiro teve que pautar obrigatoriamente as demandas dos povos indígenas em toda sua estrutura de planejamento, orçamento e gestão. Estabeleceu-se assim no seio do Estado e de suas estruturas administrativas, uma nova cultura e concepção de política indigenista, para além da cultura indigenista tutelar, assimilacionista e assistencialista. Ou seja, abriram-se novos caminhos, novas possibilidades e novas experiências de gestão pública no campo da ação indigenista do Estado, 
mesmo que as velhas culturas e práticas tutelares permanecessem, principalmente no raio de ação da FUNAI. As demandas indígenas saem da lógica assistencial e passam a ser direitos, de responsabilidade dos governos, pautando suas agendas, ainda que de modo secundário e periférico.

A Educação Escolar Indígena é a que sofreu uma radicalidade maior de descentralização, uma vez que em 1991, por decreto presidencial, a mesma foi retirada da FUNAI e transferida para o Ministério da Educação, que por sua vez, transferiu a tarefa da execução das ações aos Estados e excepcionalmente aos municípios, formando o que hoje é conhecido por Regime de Colaboração.

De modo geral, houve mudanças substantivas e positivas no conceito e no discurso do Estado e dos governos quanto aos direitos indígenas. Houve também sucessivas buscas e tentativas de mudar, criar e inovar as práticas políticas - políticas públicas - no atendimento às demandas e aos direitos indígenas, embora com poucos resultados e concretude e muita coisa abandonada pelo caminho e outras sendo destruídas. De todo modo, entendemos que o saldo no período ainda é positivo.

Olhando para os últimos governos do PSDB e do PT, o de Fernando Henrique Cardoso e os de Luís Inácio Lula da Silva e da Dilma Rousseff, respectivamente, observamos semelhanças e particularidades em suas políticas voltadas aos povos indígenas. De forma simplista diríamos que Fernando Henrique Cardoso iniciou à construção das novas bases da política indigenista à luz das novas orientações da Constituição Federal de 1988 e o governo Lula aprofundou e ampliou algumas dessas bases e criou outras. No campo da educação, Fernando Henrique Cardoso consolidou a descentralização das políticas de educação escolar indígena sob a coordenação do MEC criando a Coordenação Geral de Apoio às Escolas Indígenas (CGAEI) e o Comitê de Professores Indígenas. Esta coordenação foi compartilhada com os estados e municípios em forma de Regime de Colaboração a partir do qual empreendeu-se a Campanha Nacional pela Universalização do Ensino Fundamental, impactando fortemente no cenário das escolas indígenas com um forte crescimento no número de escolas, professores e estudantes indígenas. O governo Lula virá acelerar ainda mais esse crescimento principalmente no seu segundo mandato. $O$ governo Fernando Henrique deu início também às discussões e implementações de programas como os de formação inicial e continuada de professores indígenas no nível de ensino médio por meio do chamando Magistério Indígena e no nível de ensino superior por meio das chamadas Licenciaturas Interculturais e de produção de materiais didáticos específicos e bilingues/mutilingues. O governo Lula deu continuidade a esses programas, ampliando e aperfeiçoando-os. Ainda na gestão do governo de FHC as discussões sobre ações afirmativas programas sociais tiveram início, mas foi o governo Lula quem iniciou a implementação de várias políticas e ações. 
No campo da saúde indígena o governo de FHC consolidou as políticas de saúde indígena no âmbito do Ministério da Saúde. Criou o Subsistema de Saúde Indígena, os Distritos Sanitários Indígenas e os Conselhos Distritais de Saúde Indígena como controle social. O governo Lula deu continuidade a essa política e como decisão mais importante criou a Secretaria de Saúde Indígena (SESAI) no âmbito do Ministério da Saúde como responsável pela gestão da saúde indígena, que antes estava sob a responsabilidade da Fundação Nacional de Saúde (FUNASA).

Mas, talvez o maior legado do governo FHC no campo da política indigenista foi o número expressivo de demarcações de terras indígenas demarcadas e homologadas, principalmente na Amazônia Legal, com apoio técnico e financeiro do Programa de Proteção das Terras na Amazônia Legal (PPTAL), programa de cooperação internacional criado no âmbito da Conferência Mundial de Meio Ambiente realizada no Rio de Janeiro em 1992 (RIO92 ou ECO92) e gerenciado pela FUNAI. Associado ao programa de regularização de terras indígenas, as negociações no bojo da RIO 92, também foi criado em 1999 um projeto com apoio da cooperação internacional denominado de Projeto Demonstrativo dos Povos Indígenas (PDPI) que apoiou iniciativas de proteção e fiscalização das terras indígenas demarcadas e de iniciativas voltadas ao desenvolvimento econômico, social e cultural dos povos indígenas na Amazônia Legal. Esses dois programas foram os primeiros, após a derrubada da tutela indígena pela CF de 1988, que adotaram e promoveram a participação indígena, inclusive na governança em todas as fases dos programas. Também foram pioneiros no repasse direto de recursos públicos para comunidades e associações indígenas. Tudo isso sem ausência de resistências, tensões e contradições. É uma pena que nas gestões petistas esses programas não tiveram continuidade. De todo modo, programas importantes criados e desenvolvidos posteriormente nos governos petistas, como Carteira Indígena (MMA), Prêmio Culturas Indígenas (MINC), Programa Nacional de Gestão Ambiental e Territorial Indígena (PNGATI) todos seguiram essa metodologia participativa. O PNGATI, na verdade, foi resultado de lições aprendidas do PPTAL e do PDPI, ampliado para o plano nacional e como política pública.

Os governos petistas deixaram seus legados específicos como no campo do acesso de indígenas ao ensino superior que está estimado em mais de 35.000 em 2016, por meio de incentivos sociais de bolsas, cotas, reservas vagas, cursos específicos e outros meios. Na saúde indígena, temos a criação da SESAI. No âmbito da política indigenista mais ampla, destaca-se a criação da Comissão Nacional de Política Indigenista que em 2016 foi transformada em Conselho Nacional de Política Indigenista (CNPI). Mas, as principais marcas dos governos petistas ficaram no esforço de buscar maior diálogo com os povos indígenas e promover maior participação indígena nas políticas públicas voltadas às aldeias, que podem ser exemplificadas por meio das realizações de 
conferências nacionais inéditas como a I Conferência Nacional de Educação Escolar Indígena, a I Conferência Nacional de Política Indigenista e o Conselho Nacional de Política Indigenista e inúmeras comissões, comitês, grupos de trabalho, seminários e oficinas.

Em geral, percebemos uma gradual evolução nas políticas públicas voltadas aos povos indígenas nesses últimos anos até ao final do primeiro governo Dilma. O crescimento de recursos orçamentários, criação de estruturas administrativas e de equipes e o crescimento de atendimentos às aldeias são os principais exemplos dessa evolução.

No entanto, muitos projetos estratégicos, estruturantes modernizantes da política indigenista nunca foram assumidos por nenhum governo nessa era pós Constituição Federal 1988, como por exemplo, o Estatuto dos Povos Indígenas e a regulamentação e implementação do Instituto da Consulta e do Consentimento Prévio e Informado aos povos indígenas, conforme determina a Convenção 169/OIT, do qual o Brasil é signatário.

Além disso, a partir do segundo mandato da Dilma, percebemos tentativas e ações concretas de retrocesso e de abandono da agenda positiva que vinha se construindo. Muitos planos e propostas que vinham sendo discutidas e amadurecidas foram abandonadas ou suspensas. Ou seja, projetos estruturantes da política indigenista, muitos, mesmo com resistência dos governos anteriores, estavam em franco debate, agora saíram da agenda do governo. Destacamos como exemplo, a política dos Territórios Etnoeducacionais (Decreto 6368/2009), do Sistema Próprio de Educação Escolar Indígena e da proposta de Universidade Indígena no campo da educação; o Conselho Nacional Deliberativo de Política Indigenista, no âmbito do Ministério da Justiça; a autonomia administrativa e de gestão dos Distritos Sanitários Especiais Indígenas (DISEls), no âmbito da saúde indígena e; o fortalecimento das estruturas físicas, recursos humanos e financeiros da FUNAI principalmente nos níveis de coordenações locais e regionais.

Assim, a política indigenista, mesmo reconhecendo os avanços e as conquistas históricas, continua frágil e fortemente marginal nas políticas do Estado e dos governos. Essa fragilidade, inércia e marginalidade política, é resultado de uma visão e opção dos governos de privilegiar os interesses das elites econômicas e políticas, que interessados nas terras indígenas e nos recursos naturais nelas existentes, tornam os governos reféns para não atenderem os direitos indígenas, ignorando e descumprindo a Constituição Federal.

CIMEAC: A educação intercultural indígena aparece, num primeiro momento, associada à educação bilíngue e, posteriormente, ao contexto da educação superior, por meio das Licenciaturas Interculturais Indígenas. Outras políticas de ações afirmativas como o PROUNI e a "lei de cotas" ampliam a possibilidade de acesso ao ensino superior desse segmento, mas não seguem 
as mesmas premissas dos casos anteriores, já que preveem a inclusão num sistema (epistemológico e pedagógico) muitas vezes heterogêneo a seu modo de vida originário. Tendo em vista a crescente demanda indígena pelo ensino escolar e universitário, quais são os ganhos e os desafios enfrentados pelos povos indígenas ao ingressarem no ensino superior?

GJSL: As políticas públicas voltadas aos povos indígenas apresentam profundas contradições no plano conceitual e metodológico. A educação escolar indígena, como política pública, enfrenta este dilema: como tratar de forma diferenciada os diferentes, sem cair na armadilha da desigualdade. Como garantir uma educação diferenciada aos indígenas em todas as fases de seu percurso escolar e universitário. Afinal de contas o indígena continua sendo indígena em todas essas fases. Nos planos intencional e jurídico isso não deveria ser problema já que se trata de direito. Mas as instituições públicas estatais e seus dirigentes têm enormes dificuldades para entender, aceitar e garantir esses direitos, seja por ignorância, má vontade ou mesmo racismo. De todo modo, verificamos avanços ainda que pequenos e em uma velocidade muito baixa. Nos últimos cinco anos, por exemplo, algumas universidades como a Universidade Federal do Amazonas, a Universidade Federal de Goiás e outras, começaram a permitir que estudantes indígenas de graduação pudessem escrever e defender suas monografias em suas línguas indígenas. Isso parece pouco, mas, é uma gigantesca revolução no epicentro canônico da ciência ocidental.

É importante chamar atenção para o fato de que mesmo considerando o profundo etnocentrismo, eurocentrismo, cientificismo arrogante da ciência e da universidade hegemônica é necessário, desejável e é direito dos indígenas o acesso a ela. $\mathrm{O}$ acesso a Universidade traz muitos e indiscutíveis ganhos reais e potenciais aos povos indígenas, principalmente no campo da cidadania, da consciência histórica, do protagonismo e do empoderamento técnico, científico, político, econômico, cultural e autoestima cognitivo e moral. Tudo isso é necessário e útil aos indígenas não apenas para gerir com maior qualidade seus territórios em contextos cada vez mais complexos, mas também e, sobretudo, para qualifica-los e empodera-los no diálogo com a sociedade nacional e global e para o exercício pleno de cidadania. Negar aos povos indígenas o acesso à escola e a universidade é sem dúvida a pior forma de racismo e de condenação humana e sociopolítica, uma vez que tornaria o futuro existencial desses povos mais incerto, obscuro ou mesmo sem ou pouca esperança.

Milhares de indígenas encontram-se matriculados e estudando nas IES Federais, estaduais e privadas do país. O acesso ao ensino superior por indígenas não é apenas um direito; é também uma necessidade e um desejo na medida em que os povos indígenas administram hoje mais de $13 \%$ do território nacional, sendo que na Amazônia Legal este percentual sobe para $23 \%$. Não se trata apenas de garantir capacidade interna das comunidades 
indígenas para gerir seus territórios, suas coletividades étnicas e suas demandas básicas por políticas públicas de saúde, educação, autossustentação, transporte, comunicação, mas também de lhes dar condições de cidadania plena e diferenciada para dialogar com o Estado e com a sociedade nacional no que tange a interesses comuns e nacionais, como, por exemplo, a contribuição econômica dos territórios indígenas, a relevância da diversidade cultural, étnica, linguística e da sociobiodiversidade indígena que são também patrimônio material e imaterial da sociedade brasileira.

A formação superior de indígenas reveste-se de importância estratégica também para a construção de espaços e experiências de convivência multicultural entre povos indígenas e a sociedade nacional, capazes de garantir harmonia sociopolítica, levando-se em consideração a conformação recente do Brasil como um Estado pluriétnico e multicultural. Além disso, a presença indígena nas universidades pode e deveria abrir possibilidades concretas para o diálogo intercientífico ou interespistemológico entre sistemas complexos de conhecimentos indígenas e científicos. Nos últimos 30 anos, os povos indígenas vêm se constituindo como sujeitos de seu próprio destino, fazendo valer seus direitos e cobrando dos governos a constituição de um Estado diferente que possibilite a igualdade de condições de vida para todos.

Para isso, esses povos contam atualmente com convênios internacionais e leis nacionais para garantir seus direitos. Os mais significativos são a Convenção 169 da Organização Internacional do Trabalho (OIT) ratificado pelo Brasil em 2004, a Declaração das Nações Unidas (ONU) sobre os Direitos dos Povos Indígenas, adotada em setembro de 2007 pela Assembleia Geral da ONU, e a Constituição Federal de 1988, que asseguram os direitos coletivos dos povos indígenas.

Estes povos desejam formação superior em seus termos, ou seja, para atender suas demandas, realidades, projetos e filosofias de vida. Aqui reside 0 maior desafio da formação superior de indígenas nos contextos atuais das universidades, fundamentadas na organização, produção e reprodução de saber único, exclusivo, individualista e a serviço do mercado. O desafio é como esta instituição superior formadora pode possibilitar a coexistência lado a lado e a circulação, interação e reconhecimento mútuo entre distintos saberes, pautados em distintas bases e lógicas cosmológicas, filosóficas e epistemológicas. Os povos indígenas, por exemplo, não gostariam de ser enquadrados pelas lógicas academicistas que alimentam e sustentam os processos de reprodução do capitalismo individualista, que tem gerado uma sociedade cada vez mais em retorno à civilização da barbárie e da selvageria, por meio da violência, da exploração econômica desumana, do império da lei do mais rico e dos que têm poder político à base de democracias das elites econômicas e políticas racistas e excludentes.

Os povos indígenas gostariam de compartilhar com o mundo, a partir da universidade, seus saberes, seus valores comunitários, suas cosmologias, 
suas visões de mundo e seus modos de ser, de viver e de estar no mundo, onde o bem-viver coletivo é a prioridade. Os direitos indígenas no Brasil são coletivos, por isso o direito coletivo à terra. As Universidades Públicas consideram o direito de ingresso ao ensino superior de forma individualizada. A individualização dos indígenas é um risco e uma ameaça aos princípios e modos próprios de vida coletiva indígena. Do ponto de vista dos direitos coletivos dos povos indígenas, as vagas reservadas pelas IES não são dos indivíduos, mas das coletividades indígenas (comunidades e povos). Neste caso, são essas coletividades as responsáveis pelas escolhas dos seus candidatos e dos cursos de seus interesses, assim como pelo acompanhamento de todo o processo de formação e de sua reinserção à comunidade. Isso não é tão difícil assim.

Em geral, o que acontece é que a comunidade indígena luta e conquista as políticas (vagas), mas depois quem se beneficia dessas conquistas são indivíduos que muitas vezes não têm nenhum ou pouco compromisso com a comunidade.

Considerando as experiências atuais, não existe algo tão individualista quanto o princípio da autodeclaração, pois ele nega totalmente a autonomia coletiva dos povos indígenas. Entendemos que o princípio da autodeclaração tem sua relevância, mas não pode ser a única forma de identificação étnica. Deveria ser associada a outros instrumentos de declaração ou identificação, como de pertencimento etnoterritorial ainda que como memória histórica, linguística e o reconhecimento de seu povo de pertencimento. Recentemente o Ministério Público Federal do Amazonas abriu um precedente interessante quanto a isso ao desautorizar a autodeclaração étnica de um suposto indígena Waimiri-Atroari a pedido coletivo do povo Waimiri-Atroari que não o reconhecia como membro, depois de um processo de estudo interno minucioso.

Os povos indígenas possuem seus processos educativos próprios, em alguns casos muito distintos das escolas não-indígenas, estimulados pela legislação brasileira que Ihes possibilita uma educação escolar específica e diferenciada. Como o indígena que estudou em uma escola específica, bilíngue, intercultural e diferenciada (currículo diferenciado), que foi alfabetizado na sua língua materna e tem esta como primeira língua pode concorrer em pé de igualdade com outros estudantes que estudaram em escolas regulares de língua portuguesa em processos seletivos ou mesmo em aulas ministradas unicamente na língua portuguesa?

Como se pode perceber há uma incoerência e contradição na política quando, ao mesmo tempo em que reconhece o direito específico e diferenciado aos povos indígenas, limita ou impede o exercício pleno desse direito impondo uma uniformização no acesso a outras políticas públicas de seu interesse. 
CIMEAC: Tendo em vista as diversas possibilidades de tensão cultural entre as experiências vividas na aldeia e na cidade, quais são os impactos na vida dos indígenas que por ventura adentram na vida acadêmica? E como essa saída da aldeia é vivenciada pela comunidade?

GJSL: Todo contato novo entre sujeitos de culturas distintas provoca impactos e os impactos geram novos sujeitos. Novos sujeitos não implica negação dos sujeitos anteriores, mas sujeitos com novos domínios, contextos, horizontes, possibilidades e oportunidades que o contato e os impactos oferecem. A diversidade cultural é parte histórica e orgânica na vida milenar dos povos indígenas, com todas as suas implicações. Os povos indígenas apresentam enorme potencial e capacidade para lidar com as tensões interculturais, por meio da resistência e da resiliência. Diante de situações mais adversas, sabem aproveitar as oportunidades $e$ as possibilidades para resistirem e aperfeiçoarem seus modos de vida.

Assim, as diversas ocorrências de tensão cultural entre aldeia e cidade e vida acadêmica os indígenas, simbólica e concretamente conseguem revertêlas em seus benefícios, individual e coletivamente. Os sacrifícios e sofrimentos, por exemplo, são direcionados, potencializados e positivados para o alcance dos objetivos e resultados desejados. Isso explica porque os estudantes indígenas cotistas ou não apresentam menores índices de desistência, apresentam maior nível de aproveitamento, interesse, dedicação e são os que mais lutam e reivindicam seus direitos por formação escolar e universitária. É importante destacar que esta capacidade de suportar e transformar o sofrimento em força motivadora e fonte de sabedoria os índios adquirem por meio dos ritos de passagem, enquanto um processo de aprendizagem, maturação e formação do caráter da pessoa para lidar com a adversidade própria do mundo em que vivemos. Essa espiritualidade e sinergia subjetiva e cognitiva é que liga os sujeitos indígenas em qualquer espaço e tempo em que estiverem. Não existe indivíduo indígena-átomo isolado no mundo, a menos que não tenha adquirido a formação adequada, o que é perfeitamente possível e crescente, principalmente entre aqueles que por alguma razão histórica se afastaram de suas raízes e sistemas educativos tradicionais. Por isso, não há distância social, cultural e espiritual entre indígenas ou comunidades indígenas urbanas e aldeias. Quando há é porque a distância foi artificialmente ou ideologicamente construída. Neste sentido, perguntar ou se preocupar se o estudante indígena, ao se formar, irá voltar à aldeia para ajudar seu povo, como uma condição de ser indígena ou não, não tem sentido. A pergunta devida é quais as condições, estratégias e objetivos para voltar ou não. $O$ indígena formado em direito e uma vez advogado pode ajudar muito mais seu povo na defesa de seus direitos atuando nas capitais ou em Brasília onde estão os tribunais judiciários. Qualificar o indígena formado pelo seu retorno ou 
não à sua aldeia é uma forma de discriminação, preconceito, exotismo e exclusão.

As aldeias e famílias nas aldeias, em geral, têm muito orgulho de seus membros e filhos estudando nas cidades e esperam muito de suas contribuições após concluírem seus estudos, melhor será retornando a aldeia, mas, o importante não é simplesmente retornar e sim como ajudar, de perto ou de longe mantendo sua conexão.

CIMEAC: Considerando a ideia de uma escola indígena diferenciada e intercultural, como exposta em tua tese de doutorado, intitulada "Educação para manejo e domesticação do mundo entre a escola ideal e a escola real: os dilemas da educação escolar indígena no Alto Rio Negro", quais seriam os principais pontos de convergência nos diálogos interculturais de ensino e aprendizagem entre os conhecimentos tradicionais e científicos que contribuiriam para a apropriação do conhecimento científico pelo indígena?

GJSL: Uma vez superada a arrogância, a prepotência e o autoritarismo da ciência ocidental, sem dúvida os pontos de convergência entre os conhecimentos tradicionais e científicos são de verificação simples e fácil. Em primeiro lugar, as sociedades humanas, incluindo as sociedades indígenas, concebem o campo de alcance do conhecimento ao mesmo tempo limitado e ilimitado. llimitado porque está em permanente processo de construção, descobertas, invenções, interpretações e crenças dinâmicas. Limitado porque não consegue explicar e responder a todas as perguntas humanas. Em segundo lugar, em todas as sociedades humanas, incluindo as sociedades indígenas, os conhecimentos são construções humanas, ou seja, resultados de observações, experimentações (erros e acertos) e vivências de longo prazo. Então perguntamos: o que então diferencia o conhecimento científico de outros conhecimentos, para além do poderio bélico do guardião ocidental da ciência?

Os povos indígenas, que vivem orientados por cosmovisões baseadas na complementariedade dos conhecimentos, das culturas e das espiritualidades cósmicas (nada a ver com sincretismo), não apresentam nenhum problema para acessar os conhecimentos científicos. Ou seja, da perspectiva indígena não há nenhuma incompatibilidade entre os conhecimentos autodeclarados científicos, indígenas e outros conhecimentos. Em razão disso, os estudantes indígenas que adentram a vida acadêmica, apropriam-se ao máximo que podem, muitas vezes até o que não deveriam, dos conhecimentos científicos e técnicos a partir de um filtro que fazem de acordo com suas demandas e interesses individuais e coletivos. Os estudantes indígenas nunca saem das universidades com menos conhecimentos, pelo contrário, sempre com muito mais conhecimentos, pois além dos conhecimentos tradicionais que já carregam e aperfeiçoaram ao longo da vida universitária agora somam a isso os novos conhecimentos adquiridos na 
universidade, sempre em seus termos. O mesmo não acontece com a ciência ou a universidade que nada ou quase nada aproveita dos muitos conhecimentos que os estudantes indígenas portam e circulam invisivelmente por seus corredores e salas de aula. Se a ciência ocidental adotasse também a lógica da complementariedade de saberes, todos sairiam ganhando. Se a ciência não é perfeita e absoluta ao complementar seu portifólio limitado de conhecimentos com outros conhecimentos, ela ficaria mais rica, mais forte e menos incompleta. Este é o desafio e ideal de uma interculturalidade mais radical, ou de uma inter-epistemologia ou intercientificidade, muito além da interdisciplinaridade ou transdisciplinaridade.

CIMEAC: No Brasil, já vem se discutindo há certo tempo a possibilidade de criação de uma Universidade Indígena Intercultural. Em junho de 2016 a Unicamp assinou um convênio com o povo Paiter Suruí de Rondônia com vistas à criação de uma universidade indígena em seu território. Há também, em fase propositiva, a possibilidade de criação da Universidade Indígena do Rio Negro (UIRN), por meio de parcerias com a UFAM, a FOIRN e o grupo de mestres indígenas do Rio Negro. Como o senhor avalia essas medidas e a sua execução? Como o fato de haver mais de 300 etnias indígenas no Brasil repercute nesse tipo de decisão?

GJSL: Não conheço as duas iniciativas citadas. Por isso não sei quais são as suas verdadeiras intenções e seus propósitos concretos para analisar suas potencialidades. $O$ que posso dizer é que se trata de um debate que vem crescendo nos últimos 20 anos. A primeira iniciativa concreta com alcance nacional no campo do debate foi a do Deputado Carlos Abicalil ainda no início do atual milênio, quando propôs e fez tramitar na Câmara dos Deputados um projeto de lei que visava a criação de uma Universidade Indígena. Não prosperou porque não obteve eco junto aos povos indígenas por ter sido concebido e tratado no âmbito restrito do Congresso Nacional ou junto a algumas poucas lideranças do Mato Grosso, origem do Deputado. Em 2015, o Ministério da Educação criou um Grupo de Trabalho para discutir o assunto e indicar elementos que pudessem subsidiar ações do MEC quanto ao tema. $O$ GT elaborou um conjunto de recomendações organizados em dois eixos. $O$ primeiro eixo de indicações concentrou na necessidade de consolidação e institucionalização de iniciativas já em curso no campo da formação técnica e superior de indígenas nas universidades. O outro eixo ficou centrado na concordância e na necessidade de dar curso à construção de condições técnicas, pedagógicas, políticas, financeiras e administrativas para a criação de uma Universidade Indígena, em forma de uma rede de universidades, mas com autonomia financeira, pedagógica e administrativa (gestão).

Uma característica comum percebida nas iniciativas surgidas até agora em torno da ideia de universidade indígena é que são de iniciativa e autoria 
conceitual de não indígenas, mesmo quando a demanda inicial seja dos indígenas. São os não indígenas que definem as bases pré-conceituais, filosóficas e institucionais para a ideia. Isso traz sérias limitações e fragilidades, pois indicam a grande probabilidade de que, se porventura a iniciativa prosperar e de algum modo se concretizar, se tratará, no final das contas, de uma universidade para indígenas e não dos indígenas ainda que com envolvimento e participação indígena. Deste modo, essa universidade pouco ou nada será diferente das universidades não indígenas. A principal justificativa da necessidade de Universidade Indígena é que as atuais universidades não consideram e abrem espaços para os conhecimentos indígenas e outros conhecimentos tradicionais e populares. Para mim, só será Universidade Indígena se for verdadeiramente indígena, demandada, concebida, construída, organizada e administrada/gerida por indígenas coletivamente. É claro que apoios, assessorias e parcerias serão sempre bem-vindas e necessárias. Universidade verdadeiramente indígena não significa que seja exclusivamente para indígenas. Se for de exclusividade indígena será do mesmo modo que é a universidade tradicional europeia, etnocêntrica, excludente, racista e assim por diante. Universidade Indígena precisa estar assentada sob as bases e lógicas cosmológicas, ontológicas, epistemológicas, pedagógicas e filosóficas dos sistemas civilizatórios indígenas, mas, aberta a outros sistemas de conhecimentos, culturas e civilizações. Isso significa garantir que a Universidade Indígena precisa ser operanda a partir das formas de concepção, produção, transmissão e práticas de conhecimentos indígenas, mas aberta a outras formas tantas quantas existirem no mundo. Isso precisaria estar assegurado na organização dos conteúdos, tempos, espaços, materiais didáticos e metodologias de ensino e aprendizagem. Universidade Indígena precisaria estar intrínseca e organicamente concebida, estruturada e funcionando como um espaço com processos em que os diferentes conhecimentos do mundo interagindo entre iguais e uns complementando os outros, coexistindo e convivendo lados a lado. Por isso e para isso o protagonismo, a autonomia, o empoderamento e autoria indígena é um imperativo essencial. Em função disso, penso que o primeiro passo para pensar em uma Universidade Indígena é avançar na formação superior de indígenas, principalmente no nível de pós-graduação, para formar intelectuais próprios e capacitados para ajudar, apoiar e liderar suas comunidades e povos, na construção dessa Universidade Indígena. A construção e gestão dessa Universidade Indígena precisa ser feita em diálogo com as universidades tradicionais, no mesmo nível e domínio das questões que as envolvem. Isso é muito importante, porque não se quer uma universidade como "coisa de índio para índio", mas como universidade dos indígenas do/no mundo, com o mundo e para o mundo. Pensar uma universidade indígena fechada em si mesma e afastada ou isolada de outras universidades do mundo seria uma forma de reforçar a exclusão, a discriminação e a negação histórica imposta aos povos 
indígenas em todo processo colonial. A principal justificativa da necessidade de uma Universidade Indígena é que as universidades tradicionais existentes não abrem espaços e não aceitam incorporar ou dialogar com os conhecimentos indígenas ou outros conhecimentos tradicionais. Por isso, a Universidade Indígena precisa ser muito diferente para dar conta desses diversos conhecimentos no mesmo nível de importância. Isso não significa pensar e organizar a universidade indígena fechada e isolada nas aldeias ou terras indígenas ou afastadas das outras universidades do mundo. Isso seria outra forma de exclusão, separação e negação de direitos, que os povos indígenas já viveram amargamente por imposição do poder colonial. Este tem sido um problema nas iniciativas que sugiram. Como foram guiadas por não indígenas, que embora bem intencionadas, deixaram se guiar muitas vezes por suas emoções, decepções e frustrações com suas universidades coloniais ou com a sua sociedade ou por suas conviç̧ões ideológicas e visões de mundo, acabaram idealizando a universidade indígena como uma espécie de refúgio de seus sonhos e utopias investindo em tentativas tutelistas de proteger e salvar os "pobres índios" das maldades da sociedade nacional e global das quais fazem parte as universidades. Aliás, universidade indígena significa exatamente o contrário, ou seja, uma indicação da capacidade plena dos povos indígenas de retomar as rédeas de suas autonomias societárias, com o fim do último grau da tutela que é a tutela cognitiva ou epistêmica. É necessário, portanto, ter muito cuidado e atenção para o que se está dizendo e querendo quando se está falando de universidade indígena. Muitas iniciativas que vem com este discurso, são muito boas, legítimas e necessárias, como para organizar e ofertar cursos, programas e outras atividades acadêmicas para indígenas, mas não passam de políticas de formação acadêmica tradicional, com alguns remendos de conhecimentos diversificados (parte diversificada do currículo). Para mim Universidade Indígena é outra coisa. Tem que ser outra coisa. Tem que ser muito diferente da universidade tradicional, mas não desconectada dela e muito menos indiferente ou contra ela, uma vez que para os povos indígenas os conhecimentos e as culturas são da ordem e da lógica da complementariedade, organicidade e interculturalidade, e não da exclusão, da fragmentação ou da hierarquização.

Como não se trata de uma universidade apartada, fechada, isolada do universo intracultural exclusivo dos indígenas, cabe ao Estado, por meio do MEC ou das universidades garantir as condições para sua discussão, organização e funcionamento. A Universidade Indígena tem que fazer parte da rede das universidades públicas. Ela precisa ser parte da estrutura do Estado, patrimônio do povo brasileiro do qual os indígenas fazem parte e a serviço da humanidade. 
CIMEAC: Estamos vivendo um período histórico de grande crise política, ideológica e ética. A hegemonia da lógica neoliberal ao transformar direitos em mercadorias acaba por esvaziar o humano de seus pressupostos sociais e coletivos, reduzindo-o a uma subjetividade atrelada meramente à esfera econômica. Essa produção de "seres para o consumo" atinge a todos os povos do planeta, ainda que seus efeitos sejam mais contestados por alguns, como os indígenas. De que maneira os ideais da interculturalidade crítica podem contribuir para a construção de formas de vida mais sustentáveis?

GJSL: A ideia de interculturalidade está diretamente relacionada aos princípios morais e éticos da vida expressos por meio de relações de respeito mútuo e de reciprocidade. Nessa relação o que importa são as relações entre os indivíduos e grupos e não o que elas possuem ou representam. De fato, vivemos essa crise política, ideológica, moral, ética, espiritual, humana e civilizacional pela ausência de interculturalidade e pelo império do desrespeito e do egocenstrismo. A hegemonia da lógica neoliberal e capitalista, ao transformar direitos em mercadorias acaba por esvaziar o humano de seus pressupostos sociais e coletivos, reduzindo-o a uma subjetividade atrelada meramente à esfera econômica e material. Essa produção de "seres para o consumo" atinge a todos os povos do planeta, inclusive, indivíduos ou grupos indígenas e comunidades tradicionais. Mas a força da interculturalidade cósmica e coletiva dos povos indígenas tem resistido brava e heroicamente, inclusive, pagando 0 custo dessa resistência, com a própria vida. Os povos indígenas continuam sendo massacrados, vítimas de extrema violência em suas aldeias e terras tradicionais e suas lideranças assassinadas, simplesmente por resistirem aos modos perversos e desumanos de vida capitalista. Por não aderirem às lógicas acumulativistas, predatórias, escravista e injusta da modernidade neoliberal capitalista. Como não aceitam abdicar de suas culturas tradicionais comunitárias e solidárias, de suas economias da suficiência e da partilha, de suas espiritualidades e sociabilidades do bem viver, e de seus sagrados territórios ancestrais a contracivilização da economia da barbárie, sem pudor nem humanidade, adota a cultura do mais forte, para passar por cima dos povos inteiros, para em nome do progresso e do desenvolvimento econômico que nada mais significa acúmulo criminoso de suas riquezas pessoais ou corporativas, impor a força bruta dos tratores, de estradas, hidrovias, usinas hidroelétricas, fazendas do agronegócio, garimpo, etc. Nesta sociedade moderna decadente e perdida, a soja, o gado, a energia elétrica, a indústria, o banco, a igreja valem muito mais que pessoas e povos inteiros. Tudo indica que os povos indígenas e tradicionais continuarão resistindo, como vieram resistindo durante todos os 517 anos da colonização. Essa resistência e exemplo de interculturalidade de fato e de direito dos povos indígenas não tem importância para a sociedade moderna, mas serve como exemplo e alternativa para mostrar como a modernidade não precisa ser neoliberal nem capitalista e suas barbáries. De que é possível outras formas de vida, outros mundos, 
outros valores e referências humanas e cósmicas. Outros mundos e outras formar de viver o mundo existem e oxalá que continuem existindo.

Organização: Daniela Bueno de Oliveira Américo de Godoy

\section{ENTREVISTADORES}

Beatriz Schneider-Felicio

Universidade de São Paulo (USP)

Daniela Bueno de Oliveira

Américo de Godoy

Universidade de São Paulo (USP)

\section{Danilo Seithi Kato}

Universidade Federal do Triângulo Mineiro (UFTM)

\section{Erlon Silva Honorato}

Centro de Investigações de Metodologias

Educacionais Alternativas Conexão

(CIMEAC)

Recebido em: 19/06/2017

Aprovado em: 10/07/2017 